\title{
A novel imaging system for rapid visualization of bacteria on surfaces
}

\author{
Christine Greene, MPH, PhD; ${ }^{1}$ Savannah Hatt, $\mathrm{MPH}^{2}$ \\ ${ }^{1} T S G$ Consulting, Washington, DC, USA \\ ${ }^{2}$ NSF International, Applied Research Center, Ann Arbor, MI, USA
}

\section{Corresponding author:}

Christine Greene, MPH, PhD, Senior Scientific Consultant, TSC Consulting, 1150 18th Street, NW, Suite 1000, Washington, DC 20036, USA | Chris.Greene@tsgconsulting.com

\begin{abstract}
The ability to identify locations that are missed in routine cleaning is important. Visual inspection, ATP bioluminescence systems, and fluorescence or ultraviolet light are monitoring methods that indicate overall cleanliness, but not contamination removal. In this study, we use Staphylococcus aureus to evaluate a novel imaging system that provides a rapid, visual confirmation of the presence of bacteria on surfaces at four log concentrations ranging from approximately $4.7 \times 10^{0}$ to $1.8 \times 10^{4} \mathrm{CFU} / \mathrm{cm}^{2}$. We found that the combination of the illuminator spray and imaging software was able to detect the presence of bacteria on the surfaces and indicate relative concentration by visualizing the contamination as a heat map.
\end{abstract}

KEYWORDS:

Surface contamination, monitoring, imaging, Staphylococcus aureus

\section{INTRODUCTION}

Considerable evidence exists regarding the ability of surfaces to act as a reservoir for infectious pathogens, which can pose an infection risk to those who encounter them [1]. In order for a microorganism to present an infection risk in the physical environment, it must be able to both persist in the environment and cause disease once introduced to a susceptible human host. Many human pathogens have been shown to be capable of surviving for long periods of time outside the human host. For example, methicillin-resistant Staphylococcus aureus (MRSA) has been shown to survive for up to a year on surfaces such as floors, furniture, dust and Acinetobacter baumannii can resist desiccation for as long as eight weeks [2, 3]. Several other pathogens such as vancomycin-resistant Enterococcus (VRE), Clostridium difficile and gram-negative rods have been shown to be able to survive the harsh environment for varying lengths of time posing an infection risk to patients and staff [4]. Studies have implicated environmental surfaces in the transmission of pathogens $[5,6]$. Given the role of environmental surfaces in the transmission of contamination that can either directly or indirectly contribute to healthcare-associated infections, it is important for facilities to implement a cleaning audit program to ensure adherence to the facilities' approved cleaning protocols and identify employees who may require additional training [1,4].

The most widely used audit tools for cleaning include visual inspections, fluorescent marking, adenosine triphosphate (ATP) bioluminescence and microbial swabbing. Visual inspections provide a very easy and inexpensive way for quick assessments of cleanliness, but do not allow for a reliable assessment of contamination removal [7]. ATP bioluminescence systems detect the presence of ATP on surfaces (as Relative Light Units, RLU), which correlate to the amount of organic matter present on a surface. A systematic review by Nante et al (2017) concluded that ATP bioluminescence testing was a better alternative to visual inspections, but that the limitations of this test must be considered [8]. For example, the benchmarks for the ATP systems vary widely by manufacturer, ranging from 45 RLU to 1000 RLU and the chemical residuals left behind from cleaning interacts with the test causing an artificially high or artificially low reading. Further, since the test is indiscriminate to the source of ATP, the results reflect all sources of ATP including milk, food, human cells, urine and bacteria $[9,10]$. The most accurate way to assess the presence of microbial contamination is by way of microbiological swab testing for total aerobic colony counts (ACC) expressed as colony forming units (CFU) per surface area. However, microbial swab testing is more costly, has longer turnaround times, and is often reserved for use during epidemiological investigations.

In this study, we evaluate a novel monitoring technology that offers rapid identification of the presence of bacterial contamination on a surface. This technology uses fluorescence labeling and multi-spectrum imaging. It involves the application of an illuminator spray to the surface, which contains a dye that 
binds to bacterial DNA allowing the bioburden to be visualized during the imaging process. The images are captured using a customized, multi-spectrum camera and processed using proprietary software to determine if bacterial contamination is present on a surface along with the relative amounts. The aim of this study is to assess the accuracy of this technology in detecting bacterial cells on a surface.

\section{METHODS}

\section{Microbiological methods}

Staphylococcus aureus ATCC 43300 was cultured in Tryptic Soy Broth and incubated at $35.0 \pm 1.0^{\circ} \mathrm{C}$ for $18-24$ hours for all experiments. Bacterial counts were serially diluted in Butterfield's Phosphate Buffer. In a sterile biological cabinet, $20 \mu \mathrm{l}$ of an overnight suspension were spread onto 24 individual sterilized stainless steel carriers $(2.54 \mathrm{~cm} \times 7.62 \mathrm{~cm})$ in $10^{-1}, 10^{-2}, 10^{-3}$, and $10^{-4}$ dilutions. The initial inoculum count was quantified on 12 carriers using $3 \mathrm{M}$ Petrifilm Aerobic Count Plates. Carriers were submerged in Letheen Broth and vortexed for $30 \pm 3$ seconds prior to dilution and plating.

\section{Imaging protocol}

The camera was fitted to a tripod, which remained stationary during the imaging protocol.
An initial image sequence was taken of the remaining 12 carriers before application of the illuminator spray using OptiSolve Pathfinder camera (a Canon T6 Rebel fitted with propriety attachments) for baseline images. Each slide was then sprayed with two pumps (approximately $0.1 \mathrm{~mL}$ ) of the OptiSolve Illuminator via a spray bottle and allowed to dry for 30 seconds. Once dry, each carrier was photographed again using the OptiSolve Pathfinder camera to generate image sequences after the application of the illuminator spray. All photographs were processed using the OptiSolve software which uses an algorithm to generate the final composite image.

\section{RESULTS}

Baseline images were taken of all slides after inoculation with S. aureus, but prior to the illuminator spray application (not shown). These baseline images were used to help confirm the absence of background noise, but it was very difficult to visualize the actual areas of inoculation. Once the spray was applied, areas of inoculation can be clearly seen at concentrations of $10^{4} \mathrm{CFU} /$ carrier or higher (Figure 1, C and D) and is somewhat discernible at $10^{2} \mathrm{CFU} /$ carrier followed by $10^{1}$ CFU/carrier (Figure 1, A and B).
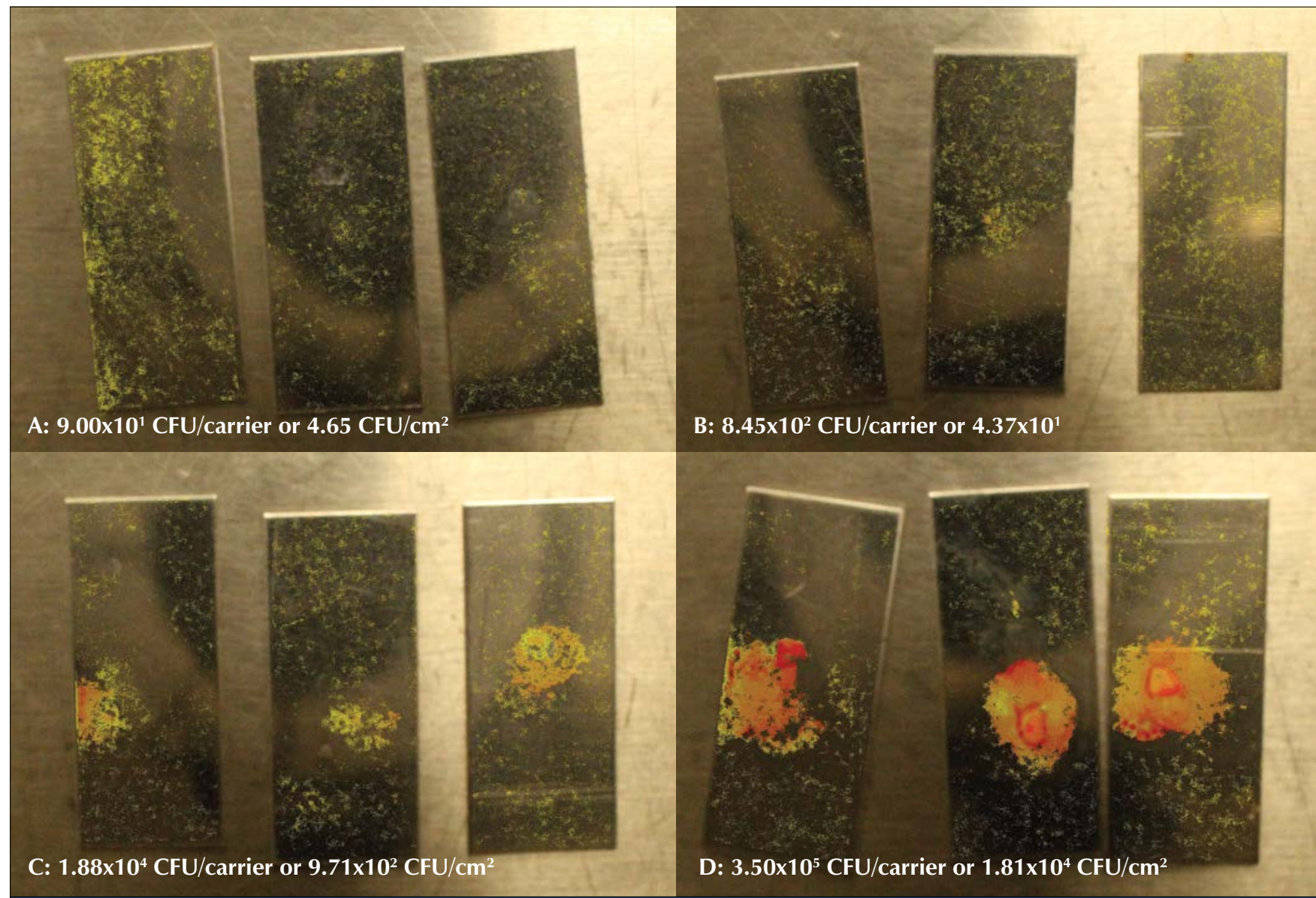

\section{B: $8.45 \times 10^{2} \mathrm{CFU} /$ carrier or $4.37 \times 10^{1}$}

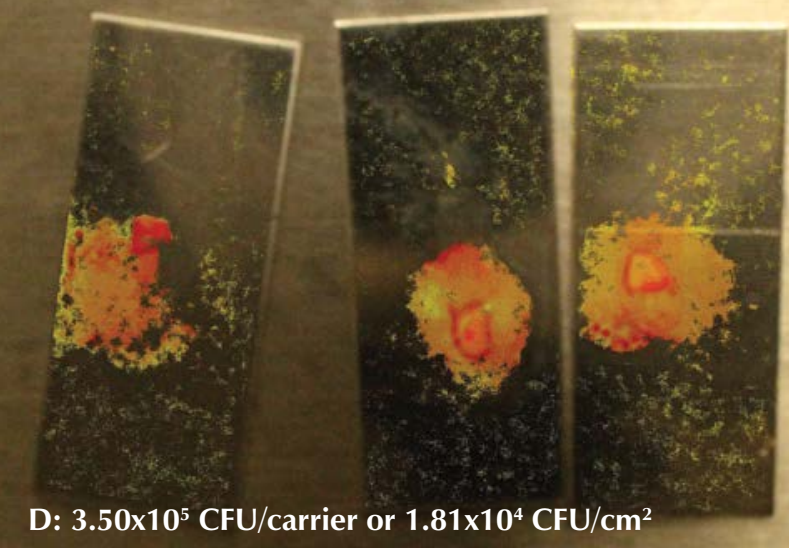

FIGURE 1: Images of carriers inoculated with Staphylococcus aureus (in triplicate) after two spray treatments with the OptiSolve Illuminator spray and visualized using the OptiSolve software. Initial inoculum concentration estimates are shown. 
The OptiSolve software indicates greater concentration of the bacteria through a heat map and colour intensity ranging from yellow (lower in concentration) to bright red (higher in concentration). For the lower inoculums $\left(10^{1}\right.$ to $10^{2} \mathrm{CFU} /$ carrier), areas of low concentration of bacteria on each carrier was visualized (yellow color). For the higher inoculums $\left(10^{4}\right.$ to $10^{5} \mathrm{CFU} /$ carrier), areas of moderate to high concentrations of bacteria was visualized (orange and red in color) with the reddest areas present on the slides with the highest concentration of inoculum $\left(10^{5} \mathrm{CFU} /\right.$ carrier), (Figure 1).

\section{DISCUSSION}

This is the first study evaluating a technology that uses fluorescence and imaging to assess bacterial contamination on inanimate objects. The ability to monitor the efficacy of cleaning processes is important since people in busy hospital environments can become exposed to infectious microorganisms from contaminated hands, surfaces, or equipment [11]. Further, high-touch surfaces can be easily missed in cleaning, disinfection, and sanitation protocols which is a concern in the case of difficult-to-clean equipment [12].

We evaluated a novel approach that uses fluorescence labelling and multi-spectrum imaging to assess microbial surface contamination. The system works by first spraying the surface with an illuminator spray containing a dye that binds to bacterial DNA, allowing for the visualization of bacteria during the imaging process. The illuminator spray was a clear liquid that was not readily visible to the naked eye once dry, nor did it leave behind any indelible marks on the stainless steel carriers used in this study. Once applied, the sprayed liquid must be allowed to dry before taking the image (approximately 30 seconds). A camera that is customized to emit various spectrums of light while capturing a sequence of images is then used to take the photograph (OptiSolve Pathfinder). The maximum field size for a single-image capture is approximately $21.59 \mathrm{~cm}$ $x 27.94 \mathrm{~cm}$, which allows for the imaging of most hightouch surface areas. The images are processed through a proprietary algorithm generating a final, composite image, which portrays the relative quantity of bacteria present in the form of a heat map, ranging from low concentration (yellow) to high concentration (red).

We tested the ability of this technology at four lowbacterial concentrations $\left(10^{1}, 10^{2}, 10^{4}\right.$ and $10^{5} \mathrm{CFU} /$ carrier) on stainless steel surfaces and found that this tool functioned as a semi-quantitative proxy to gauge relative amounts of bioburden. At lower concentrations $\left(10^{1}\right.$ and $10^{2}$ CFU/carrier), the point of inoculation on the stainless-steel carrier is less obvious - but as the inoculum concentration increases from $10^{1}$ to $10^{5} \mathrm{CFU} /$ carrier, the relative bacterial concentration can be interpreted from the density and colour of the images (Figure 1, A-D). At higher concentrations of bacteria $\left(10^{4}\right.$ and $10^{5} \mathrm{CFU} /$ carrier) areas of red, orange and yellow can be readily seen on each carrier (Figures 1, C and D). We found that the OptiSolve surface imaging technology could detect the lowest concentration of $S$. aureus tested, $90 \mathrm{CFU} /$ per carrier or $4.65 \mathrm{CFU} / \mathrm{cm}^{2}$. Since the threshold for microbial monitoring of high-touch surfaces is $\leq 2.5 \mathrm{CFU} /$ $\mathrm{cm}^{2}$ [7], additional testing would be needed to determine the sensitivity of the tool below this level. It is important to note that the camera detects the emission of the fluorescent label, which is assumed to be representative of bacterial cells on the surface. It does not directly detect the cells.

This approach could potentially provide a new, rapid way for approximating the quality of contamination removal from a surface and facilitate precision cleaning processes. However, there are some important limitations that should be taken into consideration. First, the dye used in the illuminator spray does not differentiate between live and dead cells. As such, extracellular DNA, which can be passively released from dead cells or actively released from physiologically active cells, and extracellular DNA that is prominent in a biofilm, is picked up in the imagery. Since the spray is solvent based, it cannot be used on soft, polymer or paint-coated surfaces, and must be wiped away from the surface after the image is captured, limiting the types of surfaces that can be imaged. Also, fluctuations in lighting conditions could impact signal variations and affect the resulting imagery. While we did not evaluate the safety of this product, the label bears a flammable and an irritation warning, suggesting the use of gloves and safety glasses during use.

A limitation of this study is that a pure culture of $S$. aureus was tested without the addition of artificial test soils. Therefore, our results may reflect a higher level of sensitivity than what might be seen in the environment where a variety of types of contamination, including blood, feces or other organic carbon materials are present. However, the purpose of this technology is to monitor surfaces after they have been cleaned and organic materials should have been cleaned from the surface.

The OptiSolve Pathfinder can be used as a training tool, to optimize cleaning protocols, or to identify surface locations that are missed in routine cleaning. Because it is qualitative in nature, it is not recommended to be used to validate disinfection or sterility. However, this novel technology is specific to bacteria and presents a viable alternative for assessing the overall quality of surface disinfection. Additional studies are necessary to determine if disinfectant chemical residuals on surfaces interfere with the illuminator spray, to measure the sensitivity of the technology to other bacteria as well as viruses and spores, and to evaluate the capacity for this technology to detect the impact of environmental cleaning.

\section{REFERENCES}

1. Suleyman, G., Alangaden, G., Bardossy, A.C. (2018).

The Role of Environmental Contamination in the Transmission of Nosocomial Pathogens and Healthcare-Associated Infections. Current Infectious Disease Reports, 20(6), 12. doi: 10.1007/ s11908-018-0620-2.

2. Dancer, S.J. (2009). The role of environmental cleaning in the control of hospital-acquired infection. Journal of Hospital Infection, 73(4), 378-385. 
3. Greene, C., Vadlamudi, G., Newton, D., Foxman, B., Xi, C (2016). Influence of biofilm formation and multidrug resistance on environmental survival of clinical and environmental isolates of Acinetobacter baumannii. American Journal of Infection Control, 44(5), e65-71. doi: 10.1016/j.ajic.2015.12.012.

4. Weber, D.J., Rutala, W.A. (2013). Understanding and preventing transmission of healthcare-associated pathogens due to the contaminated hospital environment. Infection Control \& Hospital Epidemiology, 34(5), 449-52.

5. Dyer, D., Hutt, L.P., Burky, R., Joshi, L.T. (2019). Biocide Resistance and Transmission of Clostridium difficile Spores Spiked onto Clinical Surfaces from an American Health Care Facility. Applied and Environmental Microbiology, 85(17), e01090-19; DOI: 10.1128/AEM.01090-19.

6. Manning, M.L., Archibald, L.K., Bell, L.M., Banerjee, S.N. and Jarvis, W.R. (2001) Serratia marcesans transmission in a pediatric intensive care unit: a multifactorial occurrence. American Journal of Infection Control, 29, 115-119.

7. Mulvey, D., Redding, P., Robertson, C., Woodall, C., Kingsmore, P., Bedwell, D., Dancer, S. (2011). Finding a benchmark for monitoring hospital cleanliness. Journal of Hospital Infection, 77, 25-30.
8. Nante, N., Ceriale, E., Messina, G., Lenzi, D., Manzi, P. (2017). Effectiveness of ATP bioluminescence to assess hospital cleaning: a review. Journal of Preventive Medicine and Hygiene, 58(2), e177-183.

9. Lewis, T., Griffith, C., Gallo, M., Weinbren, M. (2008). A modified ATP benchmark for evaluating the cleaning of some hospital environmental surfaces. Journal of Hospital Infection, 69, 156-163.

10.Boyce, J.M., Havill, N.L., Lipka, A., Havill, H., Rizvani, R. (2010). Variations in hospital daily cleaning practices. Infection Control \& Hospital Epidemiology, 31(1), 99-101.

11. Russotto, V., Cortegiani, A., Raineri, S.M., Giarratano, A. (2015). Bacterial contamination of inanimate surfaces and equipment in the intensive care unit. Journal of intensive care, 3(1), 54.

12.Messina, G., Ceriale, E., Lenzi, D., Burgassi, S., Azzolini, E., Manzi, P. (2013). Environmental contaminants in hospital settings and progress in disinfecting techniques. BioMed Research International, (429780), 8 pages. http://dx.doi.org/ 10.1155/2013/429780. 


\title{
An evaluation of conventional cleaning and disinfection and electrostatic disinfectant spraying in K-12 schools
}

\author{
B. Douglas Ford, MA; ${ }^{1}$ Keith Sopha, $\mathrm{CEM}^{1,2}$ \\ ${ }^{1}$ Canadian Association of Environmental Management, Kingston, ON, Canada \\ ${ }^{2}$ CleanLearning
}

\section{Corresponding author:}

B. Douglas Ford, MA, Senior Researcher, Canadian Association of Environmental Management, 5-447 Palace Road, Kingston, ON, Canada, K7L 4T6 Tel: 613-331-4269 | bdford42@gmail.com

\begin{abstract}
:
Background: Microbes endemic to student desks can survive for long periods and infect students. The effectiveness of conventional cleaning and disinfection practices and electrostatic disinfectant spraying were examined.

Methods: Six K-12 schools in Southeastern Ontario participated in the study. The viable microbial loads on 100 student desks were assessed via Replicate Organism Detection and Counting (RODAC) plates before and after cleaning and disinfection procedures.

Results: The adjunctive effect of electrostatic disinfectant spraying was tested on 36 desks. Mean pretest colony-forming units (CFUs) per desk were 126.8 (SD 95.7), after conventional cleaning and disinfection mean CFUs were 73.4 (SD 93.0) ( $\mathrm{t}=4.0, \mathrm{P}=0.0003$ ), and subsequent electrostatic disinfectant spraying further reduced mean CFUs to 54.2 (SD 85.0) ( $\mathrm{t}=2.6, \mathrm{P}=0.02)$. The independent effect of electrostatic disinfectant spraying without an intervening conventional cleaning step was tested on 64 desks. Mean pretest CFUs were 106.4 (SD 94.5) and after electrostatic disinfectant spraying mean CFUs decreased to 62.9 (SD 87.1) $(\mathrm{t}=3.3, \mathrm{P}=0.001)$.

Conclusions: Conventional and electrostatic disinfection methods were both effective in increasing the hygienic state of student desks. Electrostatic disinfection spraying improved hygienic state when conducted after conventional cleaning and disinfection and when used independently.
\end{abstract}

KEYWORDS:

Cleaning; Disinfection; School; Electrostatic Spray

\section{INTRODUCTION}

Schools are rife with numerous and various bacteria, viruses, and fungi $[1,2]$. Student desktops in K-12 schools are contaminated with bacteria such as Streptococcus and Staphylococcus and viruses such as influenza and norovirus [1,2]. Many bacteria and fungi pathogens can live on desks for months and influenza, common cold, and noroviruses for days [3]. Effective cleaning and disinfection of classrooms can neutralize these pathogens and reduce student absenteeism [1].

Conventional cleaning and disinfection in schools involves manually applying cleaning and disinfection solutions and wiping with cloths. This method has variable effectiveness in schools [1,2]. Spray-and-wipe cleaning and disinfection procedures in healthcare settings frequently do not achieve the desired level of decontamination [4].

Newer technologies such as ready-to-use wipes, ultraviolet light towers, and hydrogen peroxide fogging units are being used for the cleaning and disinfection of hospitals [5-7].
The electrostatic spraying of disinfectants is a newer technology, which could be readily used in schools [8]. The electrostatic sprayer sends a negatively charged plume of disinfectant that envelopes sprayed objects and the charged particles repel each other on surfaces leading to more uniform disinfectant coverage. The disinfectant plume can also reach locations where pathogens are not readily accessible to manual spray bottle and wiping procedures.

The study objective was to assess the effectiveness of conventional cleaning and disinfection and adjunctive and independent use of electrostatic spray disinfection technology on the general hygienic state of student desks.

\section{METHODS}

\section{General hygienic state sample collection}

The six schools in the study were a convenience sample from Southeastern Ontario. The 20 classrooms sampled ranged from kindergarten to high school. The viable bacterial and fungal

\footnotetext{
Acknowledgements: Mary Sopha, CleanLearning is thanked for her contributions to the project which included photography and aiding in data collection.

Funding: The research was funded by Clorox Professional Products Company Canada in the form of an Unrestricted Educational Grant to the Canadian Association of Environmental Management.
} 


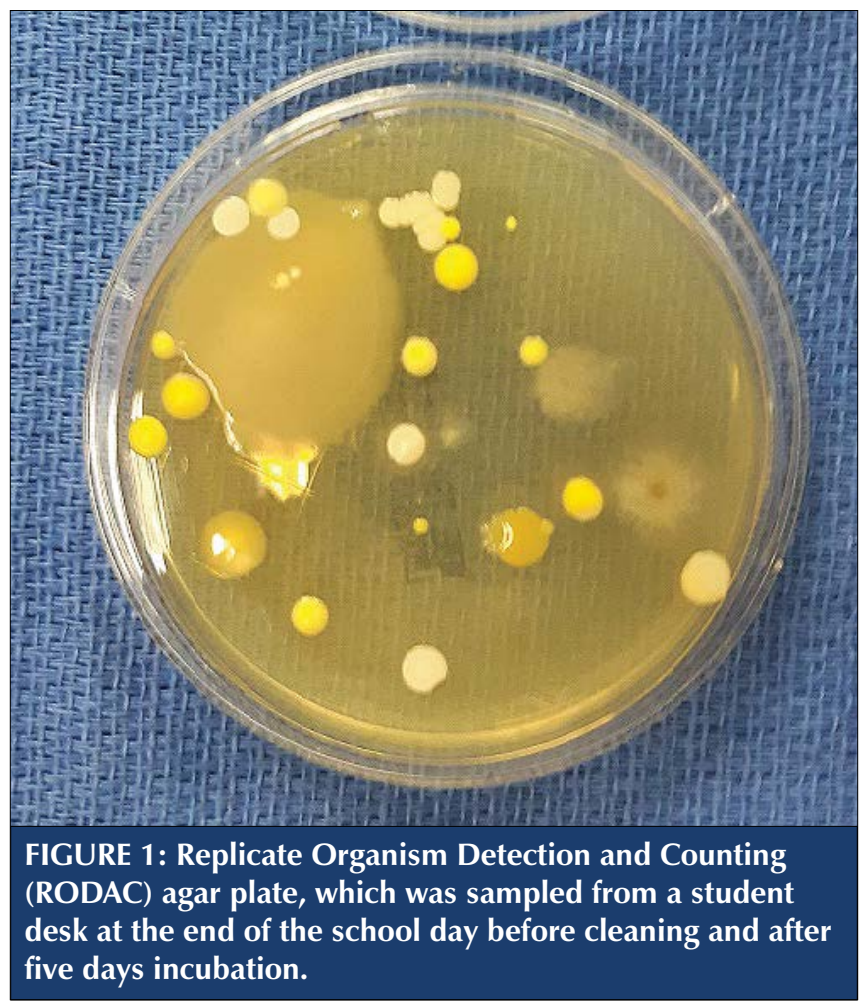

loads on 100 student desks were assessed using Replicate Organism Detection and Counting (RODAC) agar plates. Thirty-six desks were sampled at baseline, after conventional cleaning and disinfection, and again after electrostatic disinfection. An additional 64 desks were sampled at baseline and after electrostatic disinfection without an intervening conventional cleaning and disinfection step.

The study was conducted December 2018 to March 2019. Desks were sampled at the end of the school day before cleaning and disinfection interventions. After cleaning and disinfection interventions were conducted, RODAC sampling took place after $\sim 30$ minutes in order to allow the desks to dry completely. Sampling was conducted on the lower middle portion of desktops where students have the most contact with the desk. Pretest and later samplings on the same desk were taken close to one another. Samplings could not be taken from the exact same location due to possible contamination from the initial sampling with agar plates.

RODAC plates allow for surface sampling of bacteria and fungi which grow on the agar medium. The RODAC plate brand used was Remel Contact Sterile Tryptic Soy Agar with Lecithin and Polysorbate 80 (OXOID, Cat \# R111800). This brand provided a general assessment of microbial contamination and measured general hygienic state. The plates were in sterile packaging, stored at $2-8^{\circ} \mathrm{C}$, and transported to, within, and from schools in a cooler. Prior to use, the plates were warmed to room temperature for 15-20 minutes in the original packaging. The RODAC plate bags were opened while wearing sterile disposable surgical gloves on sterile towels. A gloved index finger was used to press the agar surface firmly against the desk for five seconds while ensuring the plate did not slide. Sample code, date, and time were written on the agar bed plate with a permanent marker. The RODAC plate samples were transported to CREM Co labs in Mississauga, Ontario (http://www.cremco.ca/) within 18-20 hours of collection and incubated aerobically at $36 \pm 1{ }^{\circ} \mathrm{C}$ for five days. Total colony-forming units (CFUs) were manually counted for each plate after incubation (Figure 1). In cases where microbial colonies were too numerous to count, a value of 250 CFUs was assigned [9].

\section{Cleaning and disinfection interventions}

School-employed custodians were instructed to clean and disinfect classrooms in their usual manner. Custodians were asked about cleaning methods and the products they used. In all schools, this method was cleaning and disinfecting in one step; referred to as one clean. Schools used spray bottles and cloths or solution, bucket, and cloth with hydrogen peroxide or quaternary ammonium solutions. Electrostatic spray disinfection technology consisted of an electrostatic sprayer and quaternary ammonium disinfectant solution containers mounted on a portable cart [8]. A skilled manufacturer's representative or a trainee under their supervision used the electrostatic spray disinfection technology to spray the classrooms.

\section{Statistical analysis}

Repeated Measures ANOVA with Dependent T-test multiple comparisons tested the effectiveness of conventional cleaning and disinfection and the subsequent use of electrostatic spray disinfection technology. The Repeated Measures analysis allowed for comparisons of the same dependent variable on the same desks for pretest, conventional, and electrostatic conditions. Dependent T-tests were also used to assess the disinfection effect of electrostatic spraying without an intervening conventional cleaning and disinfection step. Repeated Measures ANOVAs were also used to assess the differential effect of independent conventional and electrostatic disinfection procedures. The StatView 5 statistical package was used to analyze the data.

\section{RESULTS}

\section{RODAC plate control samples}

The examination of the adjunctive effectiveness of electrostatic spraying involved the use of 108 RODAC plates to assess pretest, conventional, and electrostatic conditions over 36 desks. The assessment of the independent effectiveness of electrostatic spraying, where there was no conventional cleaning and disinfection step, used 128 plates to assess pretest and electrostatic conditions over 64 desks. The first RODAC plate in each package of 10 was marked as a control sample to ensure no contamination occurred during the manufacturing, storage, sampling, and/or transportation to and from the lab. There were a total of 24 control samples and no control sample indicated any viable microbial life following incubation for five days.

\section{Adjunctive effectiveness of}

\section{electrostatic spray disinfection technology}

Cleaning and disinfection procedures, in general, decreased viable microbial counts on 36 student desks $(F=19.5, P<0.0001)$. 


\begin{tabular}{|c|c|c|c|c|c|c|}
\hline Condition Comparisons & $\begin{array}{c}\text { Mean } \\
\text { Difference }\end{array}$ & t-Value & df & $\begin{array}{l}\text { P value } \\
\text { (2-tailed) }\end{array}$ & $\begin{array}{c}95 \% \text { Lower } \\
\text { Confidence } \\
\text { Limit }\end{array}$ & $\begin{array}{c}95 \% \text { Upper } \\
\text { Confidence } \\
\text { Limit }\end{array}$ \\
\hline Pretest-Conventional Cleaning & 53.4 & 4.0 & 35 & .0003 & 26.6 & 80.2 \\
\hline Pretest-Electrostatic Spray & 72.5 & 5.1 & 35 & $<.0001$ & 43.5 & 101.5 \\
\hline $\begin{array}{l}\text { Conventional Cleaning - } \\
\text { Electrostatic Spray }\end{array}$ & 19.1 & 2.6 & 35 & .02 & 3.9 & 34.4 \\
\hline
\end{tabular}

Desktops were less contaminated after conventional cleaning and disinfection $(\mathrm{t}=4.0, \mathrm{P}=0.0003)$ and desks were even less contaminated when electrostatic spray disinfection followed conventional cleaning and disinfection $(t=2.6$, $\mathrm{P}=0.02$ ) (Table 1). Mean pretest CFUs were 126.8 (SD 95.7), after conventional cleaning and disinfection mean CFUs were 73.4 (SD 93.0), and subsequent electrostatic disinfectant spraying further reduced mean CFUs to 54.2 (SD 85.0) (Figure 2).

\section{Independent effectiveness of} electrostatic spray disinfection technology

In order to test the independent effect of electrostatic disinfectant spraying, 64 desks were sampled before and after electrostatic spraying without an intermediary conventional cleaning and disinfection step. Independent use improved general hygienic state of student desks $(t=3.3, P=0.001)$. Mean pretest CFUs were 106.4 (SD 94.5) and after electrostatic disinfectant spraying mean CFUs decreased to 62.9 (SD 87.1) (Figure 2).

The differential effectiveness of conventional cleaning and disinfection and electrostatic disinfectant spray procedures when used independently was examined. Both cleaning and disinfection methods, when used independently, were effective in decontaminating student desks $(\mathrm{F}=23.5, \mathrm{P}<0.0001)$; however, no difference in effectiveness was found between the two methods $(F=0.88, P=0.35$ ) (Figure 2).

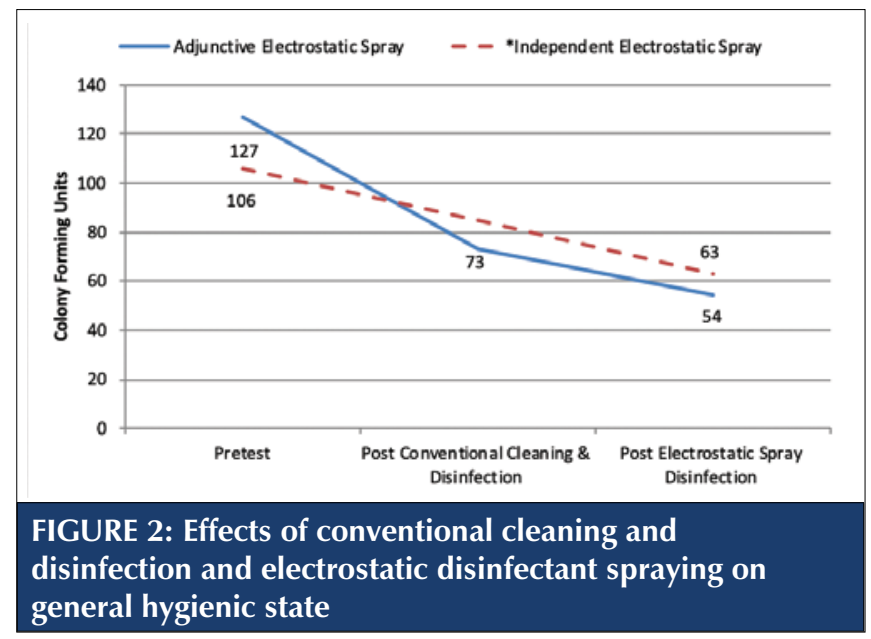

*No intervening conventional cleaning and disinfection step. Adjunctive Electrostatic Spray N = 36; Independent Electrostatic Spray N = 64 .

\section{DISCUSSION}

Student desks were found to be contaminated with viable microbes before cleaning and disinfection were conducted. This highlights the need for effective cleaning and disinfection of student desks [1,2]. Efficacious cleaning and disinfection would help to prevent the spread of infectious illnesses such as colds, pharyngitis, influenza, and intestinal ailments amongst students, teachers, and their families and community [1-3].

The results indicated conventional cleaning and disinfection procedures were effective in reducing viable microbes on student desktops. There was an additive disinfection effect when electrostatic spray disinfection followed conventional cleaning and disinfection. In schools where electrostatic disinfectant spraying was conducted without an intervening conventional cleaning and disinfection step, levels of viable microbes were decreased. Electrostatic spray disinfection technology increased general hygienic state when used independently and when used in conjunction with conventional cleaning and disinfection procedures.

When the independent effectiveness of conventional cleaning procedures and electrostatic spray were compared, no differences were found. This was for a single application and it is thought multiple episodes of electrostatic spray disinfection without intervening wiping would result in a buildup of debris on desks that would promote the growth of pathogens and reduce the effectiveness of electrostatic disinfectant spraying over time. Electrostatic spray disinfection technology is not recommended as a replacement for conventional cleaning and disinfection, rather as an adjunctive disinfection intervention. Electrostatic disinfectant spray use might be especially beneficial during influenza and other infectious outbreaks in schools to increase the frequency of disinfection. The cleaning and disinfection of healthcare settings may be more effective with the adjunctive use of electrostatic disinfectant spraying. The use of electrostatic spray disinfection technology in healthcare settings needs to be rigorously evaluated before being implemented.

In the present study, viral loads were not directly assessed as this would have been prohibitively expensive. Bacteria and fungi are generally hardier than viruses and improved hygienic state can be considered indicative of reduced viral loads [3]. RODAC plate testing, while less expensive than viral testing, was costly and limited both the number of desks that could be assessed, and the ability to examine 
differences between student grade levels and conventional cleaning practices. Issues associated with access make it difficult to conduct such research in K-12 schools. Schools are cautious with regard to student safety and one school board withdrew due to concerns about potential custodian union issues. Interestingly, in general, custodians seemed to be pleased there was interest in school cleaning and disinfection practices.

School administrators and custodial managers have the responsibility to prevent and control infectious diseases in schools and to protect students, teachers, and the public by ensuring the most effective cleaning and disinfection practices are used. A first step would be to assess pathogen types and levels in schools. The next step would be to rigorously evaluate current cleaning and disinfection practices: Equipment, detergents and disinfectants, cleaning schedules, and staff training. This research initiative, in conjunction with an extensive literature review and lab investigations would aid in the development of a best practices cleaning and disinfection program for schools. In Ontario, the Provincial Infectious Diseases Advisory Committee developed an evidence-based, best-practice document for cleaning and disinfection in healthcare settings [10]. The development of effective and standardized cleaning and disinfection guidelines and standards for schools would have both health and fiscal benefits. It is recommended the Ontario ministries of Education and Health develop evidence-based best practices for cleaning and disinfection in schools.

\section{CONCLUSION}

When used independently, both conventional cleaning and disinfection and electrostatic disinfectant spraying were successful in disinfecting student desks. Electrostatic disinfectant spraying further improved hygienic state when conducted after conventional cleaning and disinfection procedures.

\section{REFERENCES}

1. Bright KR, Boone SA, Gerba CP (2009). Occurrence of Bacteria and Viruses on Elementary Classroom Surfaces and the Potential Role of Classroom Hygiene in the Spread of Infectious Diseases. Journal of School Nursing, 26, 33-41.

2. Kwan SE, Shaughnessy RJ, Hegarty B, Haverinen-Shaughnessy U, Peccia J (2018). The reestablishment of microbial communities after surface cleaning in schools. Journal of Applied Microbiology, 125, 897-906.

3. Kramer A, Schwebke I, Kampf G. (2006). How long do nosocomial pathogens persist on inanimate surfaces? A systematic review. BMC Infectious Diseases, 6, 130. DOI: 10.1186/1471-2334-6-130

4. Sattar, S.A. (2010). Promises and pitfalls of recent advances in chemical means of preventing the spread of nosocomial infections by environmental surfaces. American Journal of Infection Control, 38, S34-40.

5. Siani H, Wesgate R, Maillard JY. (2018). Impact of antimicrobial wipes compared with hypochlorite solution on environmental surface contamination in a health care setting: A double-crossover study. Am J Infect Control, 46, 1180-1187.

6. Bolton SL, Kotwal G, Harrison MA, Law SE, Harrison JA, Cannon JL. (2013). Sanitizer efficacy against murine norovirus, a surrogate for human norovirus, on stainless steel surfaces when using three application methods. Applied and Environmental Microbiology, 79,1368-77.

7. Boyce JM. (2016). Modern technologies for improving cleaning and disinfection of environmental surfaces in hospitals. Antimicrobial Resistance and Infection Control, 5,10.

8. "Clorox Commercial Solutions Clorox Total 360 System and Solutions" Retrieved from: http://www.cloroxprofessional.ca/ products/clorox-total-360-system/

9. Maturin L, Peeler JT, 2002. Chapter 3, Aerobic Plate Count, Bacteriological Analytical Manual Online, 8th ed. U.S.F.D.A., Center for Food Safety and Applied Nutrition. Retrieved from: https://www.fda.gov/food/foodscienceresearch/laboratorymethods/ ucm063346.htm

10. Ontario Agency for Health Protection and Promotion, Provincial Infectious Diseases Advisory Committee. Best Practices for Environmental Cleaning for Prevention and Control of Infections in All Health Care Settings. 3rd Edition. Toronto: Queen's Printer for Ontario; 2018. Retrieved from: https://www.publichealthontario. ca/en/eRepository/Best_Practices_Environmental_Cleaning.pdf * 